\title{
pro.posições
}

http://dx.doi.org/10.1590/1980-6248-2017-0175

ARTIGOS

\section{Programas Brafitec e Ciência sem Fronteiras: percepção de gestores dos programas no Brasil e na França ${ }^{12}$}

\section{The programs Brafitec and Science without Borders: perception of program managers in Brazil and France}

Caroline Lievore (i)

Marizete Righi Cechin (ii)

Luiz Alberto Pilatti (iii)

(i) Universidade Tecnológica Federal do Paraná - UTFPR, Ponta Grossa, PR, Brasil. https://orcid.org/0000-0003-2448-089X, carolievore1@gmail.com.

(ii) Universidade Tecnológica Federal do Paraná - UTFPR, Guarapuava, PR, Brasil. https://orcid.org/0000-0001-7651-8082,mrcechin@gmail.com.

(iii) Universidade Tecnológica Federal do Paraná - UTFPR, Curitiba, PR, Brasil. https://orcid.org/0000-0003-2679-9191, lapilatti@utfpr.edu.br.

Resumo:
O objetivo da pesquisa é comparar os programas Brasil France Ingénieur
Technologie (Brafitec) e Ciência sem Fronteiras (CsF) quanto às características, às
exigências lançadas nos editais e à percepção de pessoas que atuam nas relações
internacionais de duas universidades que enviaram e receberam estudantes, desde o
início dos programas. O corpus documental do estudo foi construído por
entrevistas semiestruturadas realizadas no Brasil e na França. Os dados foram
tratados com análise de conteúdo. Os resultados revelam a importância de
planejamento quanto aos recursos e por parte dos órgãos regulamentadores dos
programas. Infere-se que o Programa Brafitec tem um efeito mais positivo que o
Programa CsF, por apresentar uma seleção mais rigorosa, fazer acompanhamento
do aluno no exterior, planejamento de suas atividades e oferecer a possibilidade de
dupla diplomação. Conclui-se que futuras políticas públicas de mobilidade devem
fazer uma seleção em que a instituição do aluno participe do processo, em que o
planejamento das disciplinas do exterior seja traçado antes da viagem, para
convalidações, em que o aluno seja acompanhado no exterior, para ter suporte e
orientação, e em que a experiência multicultural sirva para ampliar o idioma
estrangeiro, e não fazer dele o único foco do intercâmbio.
Palavras-chave: programas de mobilidade, internacionalização, gestão

\footnotetext{
${ }^{1}$ Apoio: Coordenação de Aperfeiçoamento de Pessoal de Nível Superior (Capes).

${ }^{2}$ Normalização, preparação e revisão textual: Douglas Mattos (Tikinet) - revisao@tikinet.com.br
} 


\begin{abstract}
:
The aim of the research is to compare the programs Brazil France Ingénieur Technologie (Brafitec) and Science without Frontiers (CsF), regarding the characteristics, the requirements of the calls and the perception of people working in the international relations of two universities that sent and received students, since the beginning of the Programs. The documentary corpus of the study was constructed by semi-structured interviews conducted in Brazil and France. The data were treated with Content Analysis. The results reveal the importance of resource planning and the regulatory bodies of the Programs. It is inferred that Brafitec Program has a more positive effect than CsF Program, because it presents a more rigorous selection, the monitoring of the student abroad, planning of its activities and the possibility of double diploma. It is concluded that future public mobility policies should make a selection in which the student institution participates in the process, in which the planning of the subjects of the exterior is traced before the trip, for validations, in which the student is accompanied abroad, for support and guidance, and that the multicultural experience serves to broaden the foreign language and language is not the only focus of the exchange.
\end{abstract}

Keywords: mobility programs, internationalization, management

\title{
Introdução
}

O governo brasileiro, através do Ministério da Educação (MEC) e do Ministério da Ciência, Tecnologia, Inovações e Comunicações (MCTIC), vem sistematicamente ampliado suas políticas com vistas a diminuir o déficit de inovação e tecnologia do país, estimulando a interação entre universidades e a internacionalização da produção científica (Guzzo, Linhares, Teodoro, \& Koller, 2015; Moritz, Moritz, \& Melo, 2013; Pereira, 2013). Políticas que promovem a internacionalização das universidades públicas brasileiras ganharam destaque com diretrizes mais expressivas nos governos de Luiz Inácio Lula da Silva (2003-2010) e de Dilma Rousseff (2011-2016).

Em suas pesquisas, Fiorin (2007), Castro \& Cabral Neto (2012) e Mari \& Thieng (2014) destacam os efeitos da internacionalização e da mobilidade sobre a ciência nacional no cenário mundial e sobre a utilização dos conhecimentos produzidos. Healey (2008) traz uma revisão da internacionalização do Ensino Superior examinando os fatores de oferta e demanda dentro do setor universitário. Moral \& Pombo (2011) e a Canadian International Development Agency 


\section{pro.posıções}

http://dx.doi.org/10.1590/1980-6248-2017-0175

$e$-ISSN 1980-6248

(2005) pesquisaram sobre o desenvolvimento social e econômico de países e regiões como consequência da pesquisa e da mobilidade financiadas. Lima \& Maranhão (2009) tratam do tema da internacionalização de forma exaustiva e colocam que a mobilidade estudantil pode exercer influência sobre quatro aspectos: político, econômico, sociocultural e universitário. Através da mobilidade, promovem-se alianças estratégicas, desenvolvimento sociocultural, aperfeiçoamento de professores e estudantes e notabilidade internacional das instituições envolvidas.

Programas de mobilidade como o Brasil France Ingénieur Technologie (Brafitec) e o Ciência sem Fronteiras $(\mathrm{CsF})$ auxiliam no processo de capacitação, além de fomentar maior interação entre cientistas brasileiros e as contrapartes estrangeiras. Para Mari \& Thieng (2014), esses programas são apontados como alternativas para a resolução de problemas ligados à ciência e à tecnologia no país.

Com a implementação do Brafitec, em 2002, foi possível estabelecer parcerias entre universidades nacionais e francesas. O objetivo foi incentivar o intercâmbio entre a França e o Brasil, aproximando estruturas curriculares e a equivalências nos cursos de engenharia.

O CsF, criado em 2011, objetivava impulsionar a expansão e a internacionalização da ciência e da tecnologia no país, usando a mobilidade de alunos de graduação e pós-graduação para o desenvolvimento nacional. O programa é tido como o maior projeto dessa natureza no Brasil.

Desde seu lançamento, o CsF é objeto de discussão no meio acadêmico, entre as quais: Pereira (2013) analisa o programa acerca dos problemas referentes à sua implementação; Mari \& Thieng (2014) discutem o pensamento gramsciano tendo como enfoque analítico o CsF; Borges (2013) busca compreender se os objetivos propostos pelo Programa CsF foram alcançados; e Ribeiro (2015) examina o CsF com uma abordagem voltada ao processo de internacionalização da educação. Os estudos relacionados ao Brafitec ainda são insipientes; tem-se Gelas (2009, 2015, 2016), que acompanha o programa desde sua criação, e Grochocki (2016a, 2016b), que estuda a contribuição e o impacto do programa nos cursos de engenharia.

Estudos comparando o CsF e o Brafitec não foram encontrados, sendo assim, o objetivo deste artigo é fazer tal comparação quanto às características, às exigências lançadas nos editais e à percepção de pessoas que atuam nas relações internacionais de duas universidades que enviaram e receberam estudantes Brafitec e CsF, desde o início dos programas. 


\section{pro.posıções}

http://dx.doi.org/10.1590/1980-6248-2017-0175

e-ISSN 1980-6248

\section{Programa Brasil France Ingénieur Technologie - Brafitec}

As bases do Brafitec foram alicerçadas entre os anos de 1997 e 2001, com o lançamento do Programa de Formação Integrada nas Escolas Francesas de Engenharia de AlunosEngenheiros Brasileiros. O programa foi demandado pelo governo brasileiro, através da Coordenação de Aperfeiçoamento de Pessoal de Nível Superior (Capes), e organizado na França pela Conférence des Directeurs des Écoles Française d'Ingénieurs (CDEFI). Em sua $1^{\mathrm{a}}$ fase, previa receber em formação na França três edições sucessivas (1999, 2000, 2001) de 100 alunos engenheiros e criar novos laços entre universidades brasileiras e escolas francesas de engenharia (Gelas, 2009).

Em 2002, a cooperação bilateral entrou na $2^{a}$ fase, mais estruturada, com um novo formato, baseado nos projetos estabelecidos em parceria entre as instituições francesas e brasileiras. Junto com o lançamento, foi apresentado um caderno de encargos e um edital com duração de dois anos lançado para todos os estabelecimentos do Brasil e da França. Os projetos passaram a ser avaliados por especialistas dos dois países, uma responsabilidade exercida por um comitê de pilotagem misto e uma coordenação científica na França e no Brasil (Gelas, 2009).

O objetivo do Brafitec no edital de 2017 foi

fomentar o intercâmbio entre instituições de Ensino Superior brasileiras e francesas e estimular a aproximação das estruturas curriculares, inclusive a equivalência e o reconhecimento mútuo de créditos obtidos nas instituições participantes, nos termos do convênio assinado entre a Capes e a CDEFI em 25 de abril de 2002 (Capes, 2017).

O Programa destina-se exclusivamente para a modalidade graduação-sanduíche em todas as especialidades de Engenharia, e prevê a mobilidade bilateral também para docentes nas equipes do Brasil e da França. Possui edições anuais, lançadas por editais Capes/Brafitec. Para participar, a instituição de Ensino Superior (IES) precisa apresentar um projeto. O edital mais recente ( $\left.n^{\circ} 13 / 2017\right)$ aceita projetos para serem desenvolvidos nos anos de 2018 e 2019, e prevê a aprovação de 15 projetos.

A proposta pode envolver até três IES; exige um plano de trabalho conjunto entre as universidades brasileiras e as francesas; um planejamento de atividades para dois anos, podendo ser prorrogada por mais dois anos; cada IES envolvida no projeto deve ter um coordenador com título de doutor, obtido há pelo menos quatro anos, com equipe de trabalho composta por 


\section{pro.posıções}

http://dx.doi.org/10.1590/1980-6248-2017-0175

\section{$e$-ISSN 1980-6248}

no mínimo dois doutores; a IES onde atua o coordenador deve estar vinculada a um Programa de pós-graduação reconhecido e recomendado pelo MEC.

O primeiro projeto Capes/Brafitec, no Brasil, no 001/2003, foi enviado por três IES Centro Federal de Educação Tecnológica do Paraná, Pontifícia Universidade Católica do Paraná e Universidade Federal do Paraná, em parceria com a Universidade Tecnológica de Compiègne (UTC), Universidade Tecnológica de Troyes e Universidade Tecnológica de Belfort-Montbéliard. De 2003 até 2014, foram 204 projetos aprovados no Brasil; 2011 foi o ano com maior número de projetos aprovados (40 projetos) e 2006 o único ano em que não se teve projeto aprovado (Capes, 2016).

São 53 IES brasileiras e 54 francesas envolvidas, com participação de mais de 300 professores brasileiros e mais de 250 franceses (Grochocki, 2016b). Em janeiro de 2016, eram 73 projetos vigentes (Gelas, 2016). A vigência de cada projeto é regida pelo edital do Capes/Brafitec, e a cada edição do edital há ajustes no programa. Os requisitos para alunos participarem do Brafitec são estipulados pelo programa em nível nacional e também pela IES à qual o aluno pertence (Capes, 2017).

Do lado brasileiro, o edital mais recente exige que o candidato para o intercâmbio tenha obtido no mínimo 600 pontos no Exame Nacional de Ensino Médio (Enem), realizado a partir de 2009 , e que tenha integralizado no mínimo $40 \%$ e no máximo $80 \%$ do currículo previsto para seu curso. Também pelas regras do programa, o estudante deve estar regularmente matriculado em um curso de Engenharia e apresentar comprovante de proficiência B1 em língua francesa, certificado por testes reconhecidos internacionalmente (Capes, 2017).

Do lado brasileiro, três apoios financeiros estão previstos: Missão de Trabalho, Missão de Estudo e Material de Custeio. O primeiro diz respeito à ajuda de custo para membros do projeto, o segundo refere-se ao estudante e o último trata de recursos concedidos por ano e por projeto para despesas com aquisição de material de consumo.

No sentido Brasil/França, o último edital da Capes/Brafitec prevê duas missões de trabalho ao ano e por projeto, não inferior a 7 dias e não superior a 20 dias, para membros do projeto. Apenas o coordenador do projeto poderá realizar missão de trabalho em anos consecutivos; um membro da equipe que não seja coordenador deve ter intervalo de dois anos para participar de uma missão dessa. 


\section{pro.posições}

http://dx.doi.org/10.1590/1980-6248-2017-0175

\section{$e$-ISSN 1980-6248}

No sentido Brasil/França, a missão de estudo refere-se a despesas como bolsa no exterior, auxílio instalação, seguro-saúde, adicional de localidade, auxílio material didático e auxílio deslocamento.

Além da missão de estudos, a Capes poderá financiar a Français Langue Étrangère (FLE) para alunos nos níveis A1, A2 e B1, desde que a IES francesa considere necessário e organize a inscrição do estudante. Alunos com nível A1 e A2 podem ter financiamento de até dois meses de curso FLE, e alunos B1 de até um mês. Alunos a partir de B2 não têm o curso FLE financiados pela Capes.

No sentido França/Brasil, a missão de estudo refere-se à bolsa de estudo mensal no valor de $\mathrm{R} \$ 830,00$, para um período mínimo de 4 meses e máximo de 10.

No XII Fórum Brafitec, realizado em junho de 2016, Jacques Gelas, criador do Pré-Brafitec, coordenador francês do Brafitec e representante da CDEFI, apresentou o número total de alunos, até 2015, que participaram do programa no sentido Brasil/França (6.821) e no sentido França/Brasil (2.279).

Segundo Gelas (2015), o aumento progressivo da mobilidade de alunos brasileiros para a França se dá, pelo lado brasileiro, pelo forte apoio da Capes na concessão de bolsas de estudos; pelo lado francês, pela concessão de bolsas oriundas de empresas, de estágio, de bolsas locais, da bolsa Eiffel, entre outras. Houve significativo aumento de mobilidade em 2012, justificado pela integração do Brafitec ao Programa CsF (Gelas, 2015), pois o CsF ampliou a disponibilidade de recursos para o Brafitec (Grochocki, 2016a). Os números mostram uma mobilidade menor dos estudantes franceses para o lado brasileiro. Entretanto, a partir de 2011, o percentual aumentou, porque, além do apoio financeiro do lado Francês, o Brasil, através da Capes, passou a dar apoio monetário. Grochocki (2016a) comenta que "as IES brasileiras não têm apresentado o mesmo grau de sucesso na oferta de estágio aos estudantes franceses” (p. 66). Esse entrave pode ser um fator considerado pelo estudante estrangeiro quando avalia o Brasil como um destino, pois o estágio na França é parte do currículo dos cursos de engenharias, é viabilizado pelas IES francesas, sendo ofertado tanto para o estudante estrangeiro como para o francês, sem distinção, o que não ocorre no Brasil.

A bilateralidade do Programa Brafitec permite uma motivação aos estudantes no aprendizado da língua. Grochocki (2016b) apresentou no Fórum Brafitec de 2016 a informação de que $91,4 \%$ dos estudantes brasileiros sentiram-se totalmente motivados para aprender o 


\section{pro.posıções}

http://dx.doi.org/10.1590/1980-6248-2017-0175

$e$-ISSN 1980-6248

idioma francês, enquanto $56,8 \%$ dos estudantes franceses sentiram a mesma motivação em relação ao idioma português. O fato de o Brafitec mobilizar estudantes para aprender idiomas é um aspecto do programa que possivelmente tem efeito a médio e longo prazo, promovendo a rede de relacionamentos e a parceria acadêmica e textual.

Os cursos de Engenharia que têm maior participação no Brafitec são os de Engenharia Mecânica, Elétrica, Civil e de Produção. Embora o Brafitec seja bem estruturado (Briot, 2015) e apresente números significativos no intercâmbio e na mobilidade estudantil, na avaliação de Grochocki (2016a, 2016b), melhorias na divulgação dos dados públicos do programa podem ser implementadas nas ações para um maior equilíbrio na emissão de dupla-diplomação, na amplitude das oportunidades de estágio no Brasil, na expansão do programa para as regiões Norte e Centro-Oeste, na mobilidade também para a pós-graduação e na uniformização do banco de dados das agências de fomento (Capes e CDEFI), pois cada uma conta as bolsas e os projetos com formato próprio, causando conflito de dados.

\section{Programa Ciência sem Fronteiras - CsF}

O Decreto $n^{\circ}$ 7.642, de 13 de dezembro de 2011, institui o Programa CsF, com o objetivo de

propiciar a formação e capacitação de pessoas com elevada qualificação em universidades, instituições de educação profissional e tecnológica, e centros de pesquisa estrangeiros de excelência, além de atrair para o Brasil jovens talentos e pesquisadores estrangeiros de elevada qualificação, em áreas de conhecimento definidas como prioritárias.

O programa foi resultado do empenho conjunto do MCTIC e do MEC, respectivamente, através de suas respectivas instituições de fomento, Conselho Nacional de Desenvolvimento Científico e Tecnológico (CNPq) e Capes, e as secretarias de Ensino Superior e de Ensino Tecnológico.

A meta do CsF era oferecer 76 mil bolsas de estudo nos quatro anos de vigência do programa ("Requerimento n 4", 2015). Em 2013, o governo federal ampliou a proposta para 101.000 bolsas a serem fornecidas até 2014, para alunos de graduação e pós-graduação, além de atrair pesquisadores do exterior para residir e desenvolver pesquisas no Brasil ou estabelecer 


\section{pro.posıções}

http://dx.doi.org/10.1590/1980-6248-2017-0175

\section{$e$-ISSN 1980-6248}

parcerias com os pesquisadores brasileiros nas áreas prioritárias definidas no programa (“Decreto n 7.642”, 2011).

Como objetivos específicos, o Programa CsF determinou:

I - promover a formação de estudantes brasileiros, conferindo-lhes a oportunidade de novas experiências voltadas para a qualidade, empreendedorismo e a inovação em áreas prioritárias e estratégicas para o Brasil; II - ampliar a participação e a mobilidade internacional de estudantes; III - criar oportunidade de cooperação entre grupos de pesquisa brasileiros e estrangeiros; IV promover a cooperação técnico-científica entre pesquisadores brasileiros e pesquisadores de reconhecida liderança científica residentes no exterior; $\mathrm{V}$ - promover a cooperação internacional na área de ciência, tecnologia e inovação; VI - contribuir para o processo de internacionalização das instituições de ensino superior e dos centros de pesquisa brasileiros; VII - propiciar maior visibilidade internacional à pesquisa acadêmica e científica realizada no Brasil; VIII - contribuir para o aumento da competitividade das empresas brasileiras; e IX - estimular e aperfeiçoar as pesquisas aplicadas no País, visando ao desenvolvimento científico e tecnológico e à inovação (“Decreto no 7.642", 2011).

O programa previa auxílios de deslocamento, de instalação, de aquisição de material didático e seguro-saúde. O período mínimo de permanência no programa era de 12 meses, podendo ser estendido até 18 caso o aluno fizesse um curso intensivo da língua estrangeira. Para os cursos tecnológicos eram exigidos três meses de estágio em empresas ou centros de pesquisa no país de destino (“Decreto n ${ }^{\circ} 7.642$ ", 2011).

Em média, os valores concedidos pelo CsF variavam de acordo com o país de destino (considerando as taxas cobradas pelas instituições acadêmicas estrangeiras), com a modalidade de bolsa, com o período da concessão, com a área prioritária do curso, com a realização (ou não) de cursos de idiomas no exterior, com o período acadêmico no qual o bolsista se encontrava, com a localização da cidade onde a IES no exterior estava instalada, entre outros fatores ("Requerimento $n^{\circ}$ 4", 2015). Segundo o Ministro da Educação, Mendonça Filho, somando todos os auxílios, cada bolsista do CsF custava, aproximadamente, $\mathrm{R} \$ 106$ mil por ano aos cofres públicos (Saldaña, 2016).

Nos primeiros quatro anos do programa, o governo federal previu um investimento de $\mathrm{R} \$$ 4.679.296.546,563 com a distribuição de bolsas de estudo, atração de pesquisadores para o país e gastos com a gestão e a administração do programa. Somente em bolsas de estudo o investimento previsto foi de $\mathrm{R} \$ 2.010 .790 .189,62^{4}$ (MEC, 2017a).

\footnotetext{
${ }^{3}$ Valor corrigido conforme Índice Nacional de Preços ao Consumidor em janeiro/2017.

${ }^{4}$ Valor corrigido conforme Índice Nacional de Preços ao Consumidor em janeiro/2017.
} 


\section{pro.posições}

$e$-ISSN 1980-6248

http://dx.doi.org/10.1590/1980-6248-2017-0175

Entre 2011 e 2014, 101.446 bolsas foram concedidas. Em 2011 foram 3.621 bolsas, em 2012 foram 16.420, em 2013 foram 39.196 e em 2014 foram 42.209 ("Requerimento no 4", 2015). Até a última atualização feita em janeiro de 2016, das 101.000 bolsas previstas, foram implementadas 92.880, o equivalente a 91,96\% do que foi planejado (MEC, 2016), nas modalidades de graduação-sanduíche (73.353), doutorado-sanduíche (9.685), pós-doutorado (4.652), doutorado pleno (3.353), pesquisador visitante especial (775), mestrado (558), atração de jovens talentos (504) (MEC, 2017a).

As bolsas de graduação-sanduíche excederam a meta em 14,61\%. Isso porque, a partir de 2011, o Brafitec passou a fazer parte do CsF, sendo responsável pela concessão de 2.702 bolsas (49,9\% das bolsas de graduação-sanduíche para a França) no âmbito do Programa CsF. Isto equivale a 2,66\% do total das bolsas concedidas (101.446 bolsas) e torna o Brafitec o programa aderente que mais contribui para a concessão de bolsas CsF na graduação-sanduíche (Grochocki, 2016a). No entanto, as demais modalidades não alcançaram o número de bolsas inicialmente proposto pelo programa. Foram implementadas 63,04\% das bolsas de doutorado-sanduíche, $74,51 \%$ das bolsas de doutorado pleno e $72,23 \%$ das bolsas de pós-doutorado.

$\mathrm{Na}$ modalidade jovens talentos, 25,20\% das bolsas foram implementadas. $\mathrm{Na}$ modalidade pesquisadores visitantes, 38,75\%. Essas são as modalidades que mais contribuiriam com o processo de internacionalização da produção científica, sendo aconselhável, para resultados mais eficientes, serem priorizadas (Lira \& Balmant, 2014).

O relatório do Senado ("Requerimento no 4", 2015), elaborado pela Comissão de Ciência, Tecnologia, Inovação, Comunicação e Informática, apresentou o Projeto de Lei do Senado (PLS) 798/2015, em que se recomenda a permanência do Programa CsF, apesar das dificuldades fiscais. A comissão defendeu que o programa passe a ser uma Política de Estado.

Representantes do CNPq e da Capes firmaram parcerias com universidades e institutos de excelência localizadas em mais de 30 países. Destaque para os EUA, com 29,98\% dos bolsistas do programa, Reino Unido com 11,57\% e Canadá com 7,88\% (MEC, 2017a). A universidade que recebeu o maior número de bolsistas brasileiros (1.080) foi a Universidade de Toronto, no Canadá (MEC, 2017a).

Embora se considere a importância desses três países na produção científica mundial, o relatório do Senado para o CsF sugeriu, para próximas fases do programa, promover "uma 


\section{pro.posições}

http://dx.doi.org/10.1590/1980-6248-2017-0175

desconcentração, particularmente em direção aos países europeus e asiáticos, .... A medida poderia, ainda, significar redução nos valores gastos por bolsista, uma vez que os encargos cobrados pelas universidades norte-americanas são relativamente altos" ("Requerimento $n^{\circ} 4$ ", 2015, p. 51).

O CsF considerou 20 áreas prioritárias para o desenvolvimento do país, todas ligadas às ciências, às engenharias e à formação de professores. As engenharias e as demais áreas tecnológicas representam 44,78\% do total das bolsas (MEC, 2017a).

A não oferta de vagas nas áreas de Ciências Humanas e Sociais foi questionada. Contudo, a priorização é compreendida como necessária pela escassez de mão de obra qualificada nas Engenharias e áreas de Ciências da Saúde e pela necessidade de produção direta de tecnologia e inovação (Barreto, Silva, Bezerra, \& Jesus, 2013; Mari \& Thieng, 2014). Apesar das prioridades, do montante investido e dos resultados que o Programa CsF alcançou, é pouco provável que a internacionalização, por si só, amplie a inserção do país no cenário internacional (Mari \& Thieng, 2014).

Mesmo com investimentos superiores a 3 bilhões de reais, o CsF ainda não possui uma avaliação concreta e efetiva entre os objetivos propostos e os resultados alcançados. A inexistência de indicadores precisos deve-se à falta de uma estrutura administrativa adequada à grandiosidade do programa (Lira \& Balmant, 2014). Muitos estudantes perceberam a pouca supervisão das agências e da própria universidade: matricularam-se em apenas duas ou três disciplinas por semestre, e usaram o restante do tempo e do dinheiro para o "Turismo sem Fronteiras”, expressão usada pelos próprios bolsistas do programa (Lira \& Balmant, 2014).

Ainda que o Programa CsF estivesse em um processo considerado inicial, a política de intercâmbio proposta esbarrou em barreiras históricas, como os problemas estruturais dos órgãos públicos, o déficit da educação pública, as dificuldades com a língua estrangeira, a ingerência de resultados e especialmente as dificuldades financeiras (Barreto et al., 2013). O CsF foi interrompido em 2015 e sua reformulação foi proposta em 2016.

Em Nota oficial, o MEC informou que o CsF seria retomado com novo enfoque no intercâmbio de graduação (MEC, 2016). O foco seria no ensino de idiomas, no país e no exterior, com a inclusão de jovens de baixa renda e estudantes do Ensino Médio matriculados em escolas públicas. A nova versão do programa teria ênfase em bolsas de pós-graduação para mobilidade de discentes, docentes e pesquisadores, com envolvimento mais ativo das 


\section{pro.posıções}

http://dx.doi.org/10.1590/1980-6248-2017-0175

\section{$e$-ISSN 1980-6248}

instituições de Ensino Superior. No mesmo documento, o MEC cita que as concessões de bolsa foram finalizadas em 2014, quando foram publicados os últimos editais de seleção, cujos estudantes participantes concluíram suas atividades até o início de 2017, conforme já havia sido previsto no lançamento do programa em 2011. Segundo a Assessoria de Comunicação Social do MEC, o Ministro Mendonça Filho encontrou a $1^{\text {a }}$ fase do Programa finalizada e sem recursos para sua continuação, sendo necessário, para honrar os compromissos assumidos com alunos que estão no exterior, o incremento de $20,9 \%$ no orçamento do programa, passando de $\mathrm{R}$ \$ 1,4 bilhão para R\$1,8 bilhão (MEC, 2016). O Ministro reafirmou a importância que o programa representou e a necessidade de sua reformulação com o propósito de contribuir com o processo de internacionalização do Ensino Superior, da ciência e da tecnologia no país (MEC, 2016, 2017b).

O MEC concluiu que o Programa demandava alto investimento e precisava ser mais bem aproveitado, por isso, o CsF teria novo foco, agora na atração de jovens cientistas e na pós-graduação (mestrado, doutorado e pós-doutorado), e em 2017 já foram oferecidas cerca de 5 mil bolsas nessas categorias. Na Nota, o MEC cita que a Capes discutirá "novas estratégias de internacionalização e apoio à excelência nas universidades” (MEC, 2017a).

No Encontro de Pró-Reitores de Pós-Graduação, Pró-Reitores de Pesquisa e Secretários de Relações Internacionais de Instituições de Ensino Superior da Região Sul, ocorrido em março de 2017, a Capes anunciou o Programa Mais Ciência, Mais Desenvolvimento (MCMD), que deverá substituir o CsF. O MCMD terá uma política mais estruturada, agregando todas as atividades que fomentam a internacionalização, como os editais para bolsas-sanduíche e bolsas de pós-doutorado no exterior, atendendo especialmente estudantes de pós-graduação, com a participação de graduandos ligados à iniciação científica.

\section{Metodologia}

O presente estudo, de natureza aplicada, classifica-se, considerando a abordagem do problema, como qualitativo e, em função dos objetivos estabelecidos, exploratório. O método utilizado foi comparativo que, na visão de Marc Bloch, quando aplicado no campo das ciências humanas, consiste em examinar as semelhanças e as diferenças entre elementos comparados que constituam duas séries de natureza análoga, em meios sociais distintos (Cardoso \& Brignoli, 


\section{pro.posıções}

http://dx.doi.org/10.1590/1980-6248-2017-0175

2002). Neste caso, os meios sociais na fala de Bloch podem ser interpretados como sociedades distantes no tempo e espaço, mas que apresentam similitudes, possibilitando a pesquisa de processos sociais específicos. No método comparativo, Bloch (2002) identificou dois momentos intrínsecos: um referente à identificação das semelhanças entre os fenômenos e outro contrastivo, em que se observam as divergências entre os casos. Nesta pesquisa foram considerados ambos os momentos.

Para consecução do método comparativo, utilizou-se Schneider \& Schmitt (1998), que sugerem a adoção dos seguintes passos: (i) a seleção de duas ou mais séries de fenômenos que sejam efetivamente comparáveis, representados pelos programas de intercâmbio CsF e Brafitec; (ii) a definição dos elementos a serem comparados - as características, as exigências dos editais e a percepção de pessoas que atuam nas relações internacionais de duas universidades que enviaram e receberam estudantes; e (iii) generalização, identificação dos elementos comuns nos dois casos analisados, respeitando suas especificidades.

Como procedimentos para a coleta de dados, a pesquisa adotou a aplicação de entrevistas semiestruturadas. As entrevistas ocorreram entre os meses de abril e setembro de 2017, realizadas pessoalmente e por Skype, gravadas e transcritas. Os entrevistados são servidores de duas universidades que participaram ativamente dos dois programas objeto deste estudo. Participaram das entrevistas cinco profissionais, sem saturação devido ao universo limitado de atores que possuem conhecimento aprofundado dos objetos comparados. Fontanella, Ricas \& Turato (2008) apontam que, em estudos qualitativos, o mais significativo nas amostras intencionais não é a quantidade de entrevistados, mas a representatividade destes elementos e a qualidade das informações obtidas.

$\mathrm{Na}$ apresentação dos resultados, para garantir o anonimato, os entrevistados foram codificados como Entrevistado (E) e numerados de 1 a 5. Os três entrevistados brasileiros, aqui caracterizados como E1, E4 e E5, atuam na Universidade Tecnológica Federal do Paraná (UTFPR), e os entrevistados franceses, caracterizados como E2 e E3, atuam no setor de Relação Internacional da UTC, localizada em Compiègne, França. Importa ressaltar que, de toda a amostra, o E3 se recusou a responder questões relativas ao Programa CsF, apesar de conhecê-lo, por não atuar no setor na vigência do programa. Uma sexta pessoa foi contatada, mas se recusou a participar da pesquisa. 
Foi elaborado um roteiro de entrevista semiestruturado que permitiu obter a percepção dos envolvidos nos programas Brafitec e CsF, traçando uma comparação. Então, indagações foram feitas sobre as vantagens e desvantagens de cada um, sobre problemas relativos a eles, e compararam-se a seleção dos candidatos, o desempenho no estrangeiro e o impacto do retorno para a vida acadêmica do intercambista.

Para o tratamento dos dados, utilizou-se a técnica de análise de conteúdo (Bardin, 1977). As etapas que fundamentam a análise de conteúdo são: (i) pré-análise, (ii) exploração do material e (iii) tratamentos dos resultados, inferência e interpretação (Bardin, 1977). Cada entrevista, depois de transcrita, foi analisada seguindo a decifração estrutural, para compreender a parte do interior da fala do sujeito. Depois, fez-se a análise temática, buscando compreender a lógica específica de cada fala. Para agrupar temas semelhantes espalhados em uma mesma entrevista e entre as diferentes entrevistas, utilizou-se o recorte de fragmentos, agrupando-os tematicamente em categorias iniciais, intermediárias e finais.

Das 41 categorias iniciais, foram construídas 7 categorias intermediárias, e dessas extraiu-se as 2 categorias finais: (i) vantagens dos programas e (ii) desvantagens dos programas, as quais foram utilizadas na etapa de tratamento dos resultados, inferência e interpretação dos dados significativos e válidos a propósito do objetivo proposto.

\section{Resultados e discussões}

\section{Vantagens dos Programas}

Como vantagens do Brafitec, os entrevistados E1, E2, E4 e E5 (comunicação pessoal, 2017) citam: a seleção mais criteriosa do aluno intercambista, exigindo dele um nível de fluência no idioma francês de acordo com critérios estabelecidos pelas universidades parceiras, e não por agências governamentais, o que proporciona "mais espaço à métrica do que à política" (E4), e o envolvimento das IES em todas as fases do programa, desde a seleção até o acompanhamento dos alunos durante o intercâmbio.

Nas palavras do E2, "o processo é bem feito e os alunos são bem escolhidos”. Para o E1, esses fatores são os grandes diferenciais do Brafitec, 


\section{pro.posıções}

http://dx.doi.org/10.1590/1980-6248-2017-0175

\section{$e$-ISSN 1980-6248}

é uma relação instituição/instituição ... são duas instituições que conversam, que se conhecem e que decidem fazer um protocolo em comum, um acordo em comum. Escrevem em conjunto um processo. Acordam entre si o processo de seleção do aluno. ... as instituições, as pessoas se conhecem e existe uma confiança mútua. ... o aluno que você envia passou por critérios de exigência muito altos. Tem que saber o idioma lá. Ele não vai para fazer curso de idioma. É a instituição que valida a ida desses alunos, ela assina embaixo e confia nesses alunos, sabe que são alunos capazes e depois acompanha esse aluno (comunicação pessoal, 2017).

Outra vantagem do Brafitec é permitir a mobilidade apenas no sétimo ou oitavo período (E4). Isso significa maior maturidade e base técnica do aluno. A seleção dos alunos Brafitec tem como critérios: coeficiente mínimo de 0,8; proficiência mínima em francês B1 (70/100); ter participado do Programa Institucional de Bolsas de Iniciação Científica e/ou estágio em empresa e/ou monitoria; não apresentar reprovação no curso até aquele momento. Ou seja, alunos Brafitec têm "bons conhecimentos e habilidades, mas também atitude e autonomia, para enfrentar uma mobilidade internacional" (E4).

Com essa sistemática, o Brafitec fomentou maior cooperação institucional e estratégica sobre um domínio específico, o da Engenharia, propiciando a efetivação de vários duplos diplomas e uma relação de confiança interinstitucional construída ao longo dos anos (E1, E4 e E5). Como envolve as coordenações dos cursos de engenharia, há maior possibilidade de inovação na área, uma vez que são trocadas experiências nas visitas e nos fóruns anuais (E4). Stallivieri (2004) ressalta que, no processo de cooperação interinstitucional, é importante o reconhecimento dos sujeitos que protagonizam a cooperação, o efetivo planejamento e a precisão nas atividades e nos prazos de execução, além do processo de avaliação das ações propostas e implementadas.

O Brafitec também possibilita ao intercambista, quando tem convênio específico, a dupla diplomação. Existe um plano de ação que permite a convalidação das disciplinas previamente escolhidas, completando a grade do curso do país de origem. Há compromisso em executar o plano, pois existe um forte controle sobre as ações do aluno (E1 e E2).

Essa cooperação interinstitucional ocorre de maneira eficaz no Programa Brafitec, visto que há uma troca de conhecimentos e de experiências entre alunos, professores e coordenadores de cursos, fortalecendo parcerias em pesquisas e entre programas. Para E4, "uma relação de longo prazo no tocante ao ensino das engenharias pode evoluir para projetos comuns de pesquisa e intercâmbios de docentes entre os países". Com essa relação, o Brafitec cumpre o 


\section{pro.posıções}

$e$-ISSN 1980-6248

http://dx.doi.org/10.1590/1980-6248-2017-0175

objetivo proposto de "fomentar o intercâmbio entre IES brasileiras e francesas e estimular a aproximação das estruturas curriculares" (Capes, 2017).

$\mathrm{Na}$ mesma linha de pensamento, o E3 aponta como grande vantagem do Brafitec "o poder da cooperação entre os estabelecimentos franceses e os brasileiros, especificamente nas engenharias. ... é um Programa criado para a troca de conhecimentos e experiências entre programas de engenharia".

Através do Brafitec, os alunos se submetem a um semestre de estudo e outro de estágio em uma empresa francesa, possibilitando uma visão do mercado de trabalho, relacionando teoria e prática, consolidando a relação da universidade com o mundo profissional. Conforme exposto pelo E3, os estágios "são as bases da UTC e, então, os alunos devem se adaptar ao modo francês de funcionamento das empresas, de trabalhar dentro da empresa", o que é uma experiência riquíssima para o aluno Brafitec, e mais tarde seu diferencial no Brasil (E1).

O Brafitec é apontado pelos E2 e E3 como o programa de maior financiamento conhecido para um estudante estrangeiro na França, fator que "causa emulação" nos estudantes franceses: "um financiamento que para um estudante é enorme para viver na França” (E3). De acordo com Grochocki (2016a), o investimento para o Brafitec ultrapassa em média 40 milhões de reais, distribuídos em bolsas de estudos e missões de trabalho.

O fato de o estudante ser financiado com recursos relativamente altos acarreta maior comprometimento do aluno: "eu penso que os estudantes são conscientes e suas atividades são um pouco mais exigentes que os outros estudantes estrangeiros que vêm de outros países” (E3). Em síntese, o Brafitec é visto pelos entrevistados como um programa maduro e bem estruturado.

Como vantagens do Programa CsF foram citadas as novas parcerias e convênios firmados com IES até então desconhecidas pela França:

Uma coisa interessante que aconteceu com o CsF, e que foi algo positivo para nós franceses e para as universidades no Brasil, foi que ... nós tivemos alunos que descobrimos aqui, de universidades no Brasil que não conhecíamos. Foi o caso da Universidade Federal de Uberlândia, e de São Carlos. Graças a esses alunos, nós podemos abrir convênios com essas universidades ... feitos graças aos alunos que vieram pela primeira vez pelo CsF (E2, comunicação pessoal, 2017). 


\section{pro.posıções}

http://dx.doi.org/10.1590/1980-6248-2017-0175

$e$-ISSN 1980-6248

A abrangência das áreas do conhecimento e a universalização democrática foram colocadas pelos E1 e E5 como pontos positivos do CsF. "Havia uma prioridade, ... que é a área tecnológica, que para o País isso é importante. Uma inserção e financiamento de alunos em países onde a graduação é paga e dificilmente nosso aluno faria uma graduação-sanduíche, como na América do Norte e Austrália” (E1).

O CsF também facultou que alunos de pós-graduação e pesquisadores tivessem acesso a mobilidade científica (E1 e E2), algo que não acontece no Brafitec. Ao todo, para a França foram enviados 5.506 alunos de graduação $(76 \%)$ e 1.772 alunos de pós-graduação (24\%), conforme dados atualizados pelo programa em janeiro de 2016 (MEC, 2017). O fato de o aluno brasileiro chegar até a França e ter esta oportunidade acadêmica é vista como vantagem pelos E1 e E2. "O ponto positivo do CsF é a excelente abertura para os alunos brasileiros chegarem até a França, porque o CsF eu diria que dá mais possibilidades a qualquer aluno” (E2).

Outra vantagem do CsF foi o fato de ter sido o maior programa do gênero na história do Brasil. Apesar disso, embora tivesse tal magnitude e objetivos importantes para o desenvolvimento da ciência no país, na visão do $\mathrm{E} 4$, o CsF apresentou uma única vantagem: "a de inserir a internacionalização nas agendas das universidades brasileiras, dando à área o merecido espaço institucional”. Corroborando essa percepção, Castro \& Cabral Neto (2012) colocam que, de acordo com a Conferência Mundial sobre Ensino Superior, realizada pela Organização das Nações Unidas para a Educação, a Ciência e a Cultura (Unesco) em 2009, a internacionalização deve estar presente nos planos de estudo e ser incluída como tema prioritário das agendas governamentais.

As vantagens até aqui evidenciadas fortalecem a ideia de que ambos os programas podem/poderiam tornar o aluno diferenciado para o mercado de trabalho. A visão de mundo do intercambista é ampliada e, de alguma forma, o aluno traz inevitavelmente, como bagagem de seu intercâmbio, um segundo ou até um terceiro idioma (E1, E2 e E3). Contudo, infere-se que o Brafitec apresentou mais vantagens que o CsF por ter suas bases consolidadas em relações institucionais, um processo de seleção mais criterioso e um acompanhamento eficaz do aluno que desenvolvia atividades e disciplinas previamente definidas, além do estágio e da possibilidade de uma dupla diplomação quando há convênio institucional. 


\section{pro.posıções}

http://dx.doi.org/10.1590/1980-6248-2017-0175

\section{$e$-ISSN 1980-6248}

\section{Desvantagens dos Programas}

As entrevistas evidenciaram poucos fatores negativos relacionados ao Brafitec. O E3 citou a pouca flexibilidade do programa para além do planejado, causando um compromisso "forçado" em cumprir o cronograma. Outros dois fatores foram vistos como negativos: a instabilidade na oferta de bolsas e de políticas públicas que regulamentam o programa, trazendo insegurança tanto para as IES brasileiras quanto francesas (E3); e o baixo número de bolsas fornecidas por edital, reduzindo o número de projetos aprovados e, consequentemente, de estudantes, tornando o programa elitizado (E3 e E4). A elitização do programa foi vista pelo E1 como uma limitação, e não como uma desvantagem.

O E1 comentou que a mobilidade direcionada apenas à França é um limitador do Brafitec, ofertando vagas apenas na área de Engenharia e sendo aceita somente na modalidade de graduação-sanduíche. Contudo, esses fatores não significariam desvantagens se outras áreas do conhecimento desenvolvessem programas similares ao Brafitec.

As desvantagens do CsF referem-se à não participação das universidades no processo de seleção e acompanhamento dos alunos. Todo o processo é de responsabilidade do órgão financiador, a Capes, e a ineficiência da gestão prejudicou substancialmente a qualidade do programa. Para Oliveira \& Freitas (2016) e Pereira (2013), a seleção dos bolsistas não respeitou a prerrogativa das universidades de adotar processos próprios de seleção, fundamentados no mérito acadêmico.

Uma vez que a universidade não tinha poder de decisão no programa, era um acerto entre a Capes/CNPq e correspondentes dos outros países. À universidade cabia apenas certificar a situação acadêmica do estudante. Terminado o intercâmbio não havia capitalização de relação entre as instituições (de origem e de destino). A internacionalização tinha como foco o aluno, e não a instituição (E4, comunicação pessoal, 2017).

Houve também a pulverização de recursos públicos sem meta qualitativa, sem um indicador de impacto que garantisse a eficiência do programa (E4; Lira \& Balmant, 2014). Para o E4, o CsF tinha apenas uma meta: enviar 101.000 estudantes brasileiros ao exterior, mesmo sem fluência no idioma. Como consequência, se a meta era política e extremamente quantitativa, os critérios de seleção tiveram que ser tênues, viabilizando a ida de estudantes sem a necessária base acadêmica e maturidade pessoal. 


\section{pro.posıções}

http://dx.doi.org/10.1590/1980-6248-2017-0175

\section{$e$-ISSN 1980-6248}

No CsF, a Capes estipulou a participação do aluno no intercâmbio a partir do terceiro semestre.

Até quase o terceiro ano, principalmente nas Engenharias, as disciplinas são básicas em todas as formações e em todas as partes do mundo (base científica). Ou seja, uma mobilidade antes do terceiro ano é para ver o mesmo em outro lugar. ... a mobilidade acadêmica é importante justamente para possibilitar ao aluno ver o diferente, o complementar. Isto acontecerá apenas nos últimos dois anos. É neste período que se vai encontrar diferenças entre as formações de uma universidade para outra, e mais ainda entre os países (E4, comunicação pessoal, 2017).

Outro fator alusivo à maturidade acadêmica do intercambista refere-se ao corte mínimo de desempenho acadêmico do candidato ao $\mathrm{CsF}$ (único critério de desempenho). E4 lembra que a UTFPR estipulava média geral 6,0, o que significa um aluno com reprovações no curso, refletindo outra deficiência do processo de seleção do CsF. Para esse entrevistado, um aluno que não tem um histórico de sucesso na universidade do seu país, na sua língua, tem uma chance enorme de ter um desempenho muito pior no exterior, onde vivenciará um outro contexto cultural e social.

A seleção pouco rigorosa, sobretudo no que se refere ao idioma, compele o aluno a utilizar seis meses de bolsa para aprender o idioma do país (E1, E2, E4 e E5). Para o E1, isso reflete uma estratégia mal elaborada do programa: "um investimento muito alto para esses alunos fazerem cursos de idioma no exterior".

O não conhecimento da língua acarretou prejuízos no desempenho acadêmico dos alunos, sinalizando perdas de aprendizagem devido à barreira linguística (Souza, 2014). Apenas $27 \%$ dos bolsistas do CsF afirmaram ter fluência na língua do país de intercâmbio antes de realizá-lo ("Requerimento no 4", 2015). Souza (2014) ressalta que há contradição entre as requisições dos programas de mobilidade acadêmica, como o CsF, e as políticas linguísticas implantadas nas redes de ensino brasileiras. Exige-se um nível de proficiência que não faz parte do contexto educacional brasileiro, "que não prevê o ensino de língua estrangeira como uma maneira de suplantar as habilidades comunicativas necessárias ao intercâmbio" (Souza, 2014, p. 56).

A falta de planejamento das atividades executadas e das disciplinas escolhidas também foi apontada como desvantagem do $\mathrm{CsF}$. $\mathrm{O}$ aluno $\mathrm{CsF}$ não recebia nenhum acompanhamento da Capes, e ficava a seu próprio cargo a escolha de suas atividades e disciplinas, as quais que, normalmente, não eram propícias ou úteis para o aluno, tampouco para o país (E1, E4 e E5). 


\section{pro.posições}

http://dx.doi.org/10.1590/1980-6248-2017-0175

\section{$e$-ISSN 1980-6248}

Isso era percebido pelos professores na França e foi apontado pelo E2 como o fator mais nocivo do programa.

No CsF, o aluno faz tudo sozinho, ele não tem um apoio, a direção de um professor, de um coordenador que vai auxiliar na escolha de matérias... coisas assim. É como se fosse um elemento isolado, que faz a escolha de sair e a única coisa que ele tem que provar é um certo nível de francês pela Aliança Francesa para conseguir a bolsa (E2, comunicação pessoal, 2017).

Sem cobrança e acompanhamento, o aluno do $\mathrm{CsF}$ não sentia o ônus de retribuir para a sociedade o rendimento acadêmico esperado de uma mobilidade internacional (E2), tampouco de auxiliar na consolidação de um programa que tinha como objetivos contribuir para o processo de internacionalização do país, criando oportunidades de cooperação entre grupos de pesquisa brasileiros e estrangeiros (“Decreto n 7.642", 2011).

Outra negligência do CsF citada nas falas do E1 e E4 foi a não obrigatoriedade do estágio, considerado um elemento essencial para a formação complementar do aluno e que daria suporte no atendimento de um dos objetivos propostos pelo programa, que era de "contribuir com a competitividade das empresas brasileiras", visando "ao desenvolvimento científico e tecnológico e à inovação" ("Decreto no 7.642”, 2011), visto que a internacionalização está diretamente relacionada à área de ensino/educação, à inovação e à competitividade das indústrias (Ribeiro, 2015).

Com critérios rasos para participação e falta de planejamento e acompanhamento dos alunos CsF, as convalidações de disciplinas muitas vezes eram inviabilizadas (E1, E4 e E5), decorrendo em resultados pobres e quase nenhum ganho às universidades e à ciência nacional. Corroborando esse desfecho, Mari \& Thieng (2014) colocam que um dos impactos negativos, revelados pela falta de contato entre as universidades foram as situações em que os alunos chegavam às instituições estrangeiras e não encontravam disciplinas disponíveis para a sua área de conhecimento.

Outra desvantagem citada pelos E1 e E2 foi que a grande maioria das bolsas do CsF foram fornecidas para alunos de graduação, considerados pouco maduros para gerir todo o processo "sozinhos". Nessa linha de pensamento, Lira \& Balmant (2014) relatam a visão do diretor científico do Programa SciELO, Rogério Meneghini, de que a ida de estudantes de graduação ao exterior não vai fazer qualquer diferença no desenvolvimento da ciência nacional. Isso pode significar uma experiência pessoal importante e auxiliar no amadurecimento, ou trazer 


\section{pro.posições}

http://dx.doi.org/10.1590/1980-6248-2017-0175

algumas habilidades e perspectivas de futuro, mas não terá qualquer relação com a ciência propriamente dita. Um programa como o CsF, sem o devido suporte, torna-se oneroso demais para o Estado pagar.

$\mathrm{Na}$ perspectiva dos entrevistados, todos os fatores citados como desvantagens do programa abalaram as relações de confiança interinstitucionais e prejudicaram as ligações que haviam sido construídas com o Brafitec, na medida em que as universidades francesas percebiam a diferença no envolvimento e na eficiência do aluno CsF.

Escutei de instituições que não receberiam mais alunos do $\mathrm{CsF}$, que só receberiam aluno Brafitec, porque o nível do aluno era incompatível com aquilo que eles esperavam. ... alunos descomprometidos com o processo, a ponto de haver entre eles brincadeiras de "Turismo sem Fronteiras" porque não havia comprometimento. O rendimento era quase nenhum, ele retornava para a instituição e não tinha convalidação de nenhuma disciplina, não tinha ganho (E1, comunicação pessoal, 2017).

Como consequência, a imagem e a reputação do estudante brasileiro foram prejudicadas em universidades no exterior. Muitos estudantes não frequentavam as aulas e aproveitaram-se da estadia no exterior para fazer "turismo público" (E4; Lira \& Balmant, 2014). Além disso, E2 cita que, para ambos os programas, houve falta de orientação quanto à diferença cultural que existe entre Brasil e França:

é claro que há uma enorme diferença cultural, da maneira de ensinar, o aprendizado é diferente, o aluno que vem para cá ... é um choque para ele, porque no Brasil há uma maneira de estudar que é diferente da daqui, então nesse aspecto de deparar a parte cultural do aluno que vem, para que ele não passe por esse choque cultural quando ele chega na França (comunicação pessoal, 2017).

Percebe-se a preocupação por parte das universidades francesas de preparar o intercambista para a mobilidade. Segundo Oliveira \& Freitas (2016), não se reproduzem as mesmas disposições familiarizadas do país de origem no país destino. A percepção do estudante quanto ao novo país engloba múltiplas variáveis que vão desde a história familiar e pessoal, experiências de mobilidade, competências linguísticas, até traços de personalidade, como a abertura ao diferente e ao outro. Para Castro \& Cabral Neto (2012), a mobilidade não compreende apenas o movimento de deslocamento: "ela é muito mais ampla, pois é social e envolve estruturas, meios, culturas e significados" (p. 77). 


\section{pro.posıções}

http://dx.doi.org/10.1590/1980-6248-2017-0175

$e$-ISSN 1980-6248

Embora o $\mathrm{CsF}$ tenha apresentado problemas estruturais, esse ainda era um jovem programa que poderia ter sido melhorado, e não extinto. A Capes poderia utilizar do conhecimento adquirido com o Brafitec para melhorar o CsF: “o Brafitec é um programa mais maduro, ... tem mais de 10 anos. O CsF, por mais incoerente que seja, é do mesmo Ministério do Brafitec, ... e não se utilizou da expertise, do know-how que já havia sido desenvolvido pelo Brafitec" (E1).

Percebe-se que as desvantagens do CsF expostas pelos entrevistados, que corroboram alguns autores citados, excedem as desvantagens observadas no Programa Brafitec. O CsF mostrou fragilidades que iniciam desde o processo de seleção, com critérios rasos, e se estendem à falta de gestão em todo o desenvolvimento do programa. Tais desvantagens não fortalecem os vínculos entre os parceiros e trazem impactos negativos à imagem dos estudantes brasileiros e às relações construídas entre as IES.

\section{Brafitec x CsF: a comparação}

Até 2015, o Brafitec havia oferecido 9.100 bolsas de estudo, envolvendo a mobilidade tanto Brasil/França como França/Brasil. O CsF ofertou, entre 2011 e 2014, o total de 92.880 bolsas, sendo 7.279 estudantes com destino à França. Verifica-se aí um salto para o Brasil quando se trata de mobilidade estudantil, em termos quantitativos.

Sobre o processo de seleção, infere-se que o Brafitec recruta alunos com uma carga horária maior de aulas, ou seja, alunos matriculados no sétimo e oitavo período, com maior coeficiente de aproveitamento do curso, e estabelece como requisito para a seleção um grau mínimo de fluência no idioma (francês), o que já coloca o aluno em condições de se matricular em disciplinas e participar de projetos na universidade de destino. O CsF selecionava alunos que ainda estavam no terceiro período de curso, com um coeficiente de aproveitamento menor, sem exigência de proficiência na língua do país de destino, impedindo que o aluno iniciasse as atividades no começo do intercâmbio.

Quanto ao acompanhamento no decurso dos programas, o aluno Brafitec recebe orientação contínua de professores (tanto da instituição de origem quanto de destino), o que promove um melhor aproveitamento das atividades e abre possibilidades para a dupla diplomação, quando há convênio institucional. Ao contrário, o CsF, gerenciado pela Capes, não 


\section{pro.posıções}

$e$-ISSN 1980-6248

http://dx.doi.org/10.1590/1980-6248-2017-0175

acompanhava os alunos e suas atividades, permitia que o aluno definisse sua agenda sem supervisão adequada e necessária.

A cooperação institucional que fortalece laços entre as universidades e permite a troca de conhecimentos entre docentes e coordenações foi percebida pelos entrevistados apenas no Programa Brafitec. O CsF foi gerido sem a colaboração das IES, dificultando o processo de coadjuvação que forneceria as bases para o trabalho em conjunto e em prol do aluno.

Em relação ao desempenho dos bolsistas no exterior, evidentemente, com as diferenças nos processos de seleção e acompanhamento, os estudantes Brafitec tiveram melhor aproveitamento no exterior, na percepção dos entrevistados, com ganhos para as instituições na troca de experiências, mas, sobretudo, porque protagonizaram um programa que na visão dos entrevistados é de sucesso.

Quanto aos benefícios adquiridos pelos programas, infere-se que, no caso do CsF, o impacto foi predominantemente pessoal. Os estudantes tiveram uma oportunidade, muitas vezes única, de viver em outro país, conhecer uma nova cultura, aperfeiçoar um idioma, mas muito pouco aproveitaram do ponto de vista acadêmico. Já os alunos Brafitec, além dos mesmos benefícios, voltaram com uma bagagem acadêmica complementar importante (acesso às tecnologias diferenciadas) e uma experiência internacional na indústria (estágio).

Analisando os impactos ou os efeitos dos programas nas universidades brasileiras, os entrevistados entendem que o CsF não trouxe impactos para a ciência nacional ou para as IES. No entanto, por meio do Brafitec, houve um ganho de flexibilidade nos processos de convalidação de créditos, na proposta de programas de dupla diplomação, projetos de pesquisa e diversas parcerias de intercâmbio.

Com relação às alterações curriculares que poderiam ocorrer por meio das experiências vividas nos programas, pode-se concluir que nenhum deles promoveu mudanças ou atualizou estratégias docentes - o CsF devido aos motivos já relatados, o Brafitec porque ainda são poucos os professores envolvidos com o programa e são eles os agentes de mudança nos cursos dos quais participam.

A comparação dos dois programas, talvez os mais importantes da história educacional brasileira, tem lições valorosas para futuras políticas públicas, como a importância de se fazer uma seleção em que a instituição do aluno participe do processo, em que o planejamento das 


\section{pro.posıções}

http://dx.doi.org/10.1590/1980-6248-2017-0175

$e$-ISSN 1980-6248

disciplinas do exterior seja traçado antes da viagem, para convalidações, em que o aluno seja acompanhado no exterior, para ter suporte e orientação, e que a experiência intercultural sirva para ampliar o idioma estrangeiro, para dar suporte às novas descobertas, e não ser o idioma o único foco do intercâmbio.

\section{Considerações finais}

Nos dois programas avaliados neste estudo, Brafitec e CsF, denotam-se implementações significativas como políticas e projetos que visam avanços da produção científica e tecnológica no país, especialmente em algumas áreas do conhecimento, como as Engenharias. Tais programas contribuíram com a ampliação de parcerias interinstitucionais, com a sinergia de pesquisas entre Brasil e França, especialmente no caso do Brafitec, e com a mobilidade acadêmica. Mas tanto o Brafitec, mais pontual e duradouro, quanto o CsF, amplo e efêmero, revelam a importância de planejamento quanto aos recursos a serem geridos e dos órgãos regulamentadores que avaliam as edições dos programas.

Com relação às vantagens dos programas, o Brafitec apresentou um resultado mais positivo quanto à seleção rigorosa, ao acompanhamento do aluno no exterior, ao planejamento das atividades, e ao aproveitamento do aluno na convalidação de disciplinas e na dupla diplomação. Embora tenha proporções menores que o CsF, o Brafitec tem melhor estrutura logística de atuação nas fases de seleção e de acompanhamento do estudante, obtendo resultados mais satisfatórios e proveitosos às instituições.

Sobre as desvantagens dos programas, observou-se que o CsF apresenta mais desvantagens devido à má gestão e à desorganização em todas as fases, implicando um baixo aproveitamento do programa tanto para o aluno quanto para as IES envolvidas. As únicas desvantagens relativas ao Brafitec, que poderiam ser consideradas apenas limitadoras, são baixo número de vagas e a instabilidade quanto ao número de bolsas ofertadas anualmente.

Embora, nos últimos anos, tenha havido crescimento no número de alunos que realizaram intercâmbio por meio dos programas de mobilidade acadêmica, isso não garante que o objetivo de promover o avanço da ciência e da tecnologia no país tenha sido atingido. Sabe-se que o CsF terminou e que as bolsas para o Brafitec passam anualmente por uma redução escalonada, reflexos da situação econômica atual do Brasil. 


\section{pro.posıções}

http://dx.doi.org/10.1590/1980-6248-2017-0175

\section{$e$-ISSN 1980-6248}

A partir das lições aprendidas com os dois programas, é possível formular políticas públicas mais consistentes e estruturar programas capazes de mudar o panorama científico e tecnológico do Brasil.

\section{Referências}

Bardin, L. (1977). Análise de conteúdo. Lisboa: Edições 70.

Barreto, R. P., Silva, P. H., Bezerra, M., \& Jesus, M. (2013). Análise política quanto à eficiência do programa Ciência sem Fronteiras: relatos IFRN e UFRN. In IX Congresso de Iniciação Cientifica do IFRN (pp. 2240-2248), Instituto Federal do Rio Grande do Norte, Currais Novos.

Bloch, M. (2002). Apologia da história: ou o ofício de historiador. Rio de Janeiro: Zahar.

Borges, T. M. D., Araújo Júnior, L. Q., Florêncio, A. B., Agra Neto, J., Queiroz, F. C. B. P., \& Queiroz, J. V. (2013). Análise dos objetivos do Programa Ciências sem Fronteiras: ótica do graduando em Engenharia de Produção. In Anais do XIII Coloquio de Gestión Universitaria en Américas (pp. 1-17). Recuperado de http://bit.ly/2Qq2bgL

Briot, J.-P. (2015). La recherche scientifique en France, le rôle du CNRS et la coorération scientifique avec le Brésil. Culture juridique française pour les Brésiliens, 1-10. Recuperado de http://www-desir.lip6.fr/ briot/cv/recherche-cnrs-livre-fgv-2015.pdf

Canadian International Development Agency. (2005). Evaluation of the Canadian Francophonie Scholarship Program (CFSP), 1987-2005. Gatineau: CIDA.

Cardoso, C. F., \& Brignoli, H. P. (2002). Os métodos da História. Rio de Janeiro: Graal.

Castro, A. A., \& Cabral Neto, A. (2012). O Ensino Superior: a mobilidade estudantil como estratégia de internacionalização na América Latina. Revista Lusófona de Educação, 21(21), 69-96.

Coordenação de Aperfeiçoamento de Pessoal de Nível Superior. (2017). Edital Brafitec $n^{\circ}$ 13/2017. Recuperado de http://www.capes.gov.br/images/stories/download/editais/28042017-Edital-132017-BRAFITEC-CAPES-CDEFI.pdf 


\section{pro.posıções}

http://dx.doi.org/10.1590/1980-6248-2017-0175

\section{$e$-ISSN 1980-6248}

Decreto $\mathrm{n}^{\mathrm{o}}$ 7.642, de 13 de dezembro de 2011. (2011, 14 de dezembro). Institui o Programa Ciência sem Fronteiras. Diário Oficial da União, seção 1, 7.

Fiorin, J. L. (2007). Internacionalização da produção científica: a publicação de trabalhos de Ciências Humanas e Sociais em periódicos internacionais. Revista Brasileira de Pós-Graduação, 4(8), 263-281.

Fontanella, B. J. B., Ricas, J., \& Turato, E. R. (2008). Amostragem por saturação em pesquisas qualitativas em saúde: contribuições teóricas. Cadernos de Saúde Pública, 24(1), 17-27. doi:10.1590/S0102-311X2008000100003

Gelas, J. (2009). As lições e as vantagens do Programa Brafitec. In Anais do Fórum Franco-Brasileiro da Educação Superior e Pesquisa (pp. 1-10), Coordenação de Aperfeiçoamento de Pessoal de Nível Superior, Brasília, DF. Recuperado de http:/ / portal.mec.gov.br/index.php?option $=$ com_docman\&view $=$ download\&alias $=1$ 927-jacques-gelas-traducao\&category_slug=novembro-2009-pdf\&Itemid=30192

Gelas, J. (2015). Programme Brafitec. In Anais do XI Fórum Brafitec (pp. 1-10), Universidade Tecnológica Federal do Paraná, Curitiba. Recuperado de http://www.ct.utfpr.edu.br/deptos/XIforumbrafitec/apresentacoes/16.30JacquesGelas.pdf

Gelas, J. (2016). Programme BRAFITEC Brasil France Ingénieurs Technologie. In Anais do XII Fórum Brafitec (pp. 1-14), Collegium D’Ingenierie des Grandes Ecoles du LanguedocRoussillon, Montpellier. Recuperado de https://ouebe.polytech.umontpellier.fr/BRAFITEC/images/presentations/2juin/BR AFITEC_Jacques_Gelas.pdf

Grochocki, L. F. M. (2016a). A contribuição da Capes para a internacionalização das engenharias no Brasil: o caso do Programa Brafitec. Dissertação de Mestrado, Universidade Federal do Rio Grande do Sul, Porto Alegre.

Grochocki, L. F. M. (2016b). The contribution of Brafitec to the internationalization of Brazilian engineering undergraduate courses. Recuperado de https://ouebe.polytech.umontpellier.fr/BRAFITEC/images/presentations/2juin/Apr esentacao_FORUM.pdf 


\section{pro.posıções}

http://dx.doi.org/10.1590/1980-6248-2017-0175

\section{$e$-ISSN 1980-6248}

Guzzo, R. S. L., Linhares, M. B. M., Teodoro, M. L. M., \& Koller, S. H. (2015). Perspectives and challenges regarding Brazilian policies for research and postgraduate studies in psychology. Psicologia: Reflexão e Crítica, 28(supl. 1), 34-39. doi:10.1590/16787153.2015284006

Healey, N. M. (2008). Is higher education in really 'internationalising’? Higher Education, 55(3), 333-355. doi:10.1007/s10734-007-9058-4

Lima, M. C., \& Maranhão, C. M. S. A. (2009). O sistema de educação superior mundial: entre a internacionalização ativa e passiva. Avaliação: Revista da Avaliação da Educação Superior, 14(3), 583-610. doi:10.1590/S1414-40772009000300004

Lira, D., \& Balmant, O. (2014). Ao custo de R 3 bi, Ciência sem Fronteiras não tem métrica eficaz de qualidade. Último segundo. Recuperado de http://ultimosegundo.ig.com.br/educacao/2014-06-05/ao-custo-de-r-3-bi-cienciasem-fronteiras-nao-tem-metrica-eficaz-de-qualidade.html

Mari, C. L., \& Thieng, L. C. (2014). Ciência e políticas: análise do programa Ciência sem Fronteiras a partir da perspectiva gramsciana. Educação e Fronteiras, 4(11), 39-56.

Ministério da Educação. (2016). Nota oficial: Aluno de baixa renda passa a ter a atenção do Ciência sem Fronteiras [Nota on-line]. Recuperado de http://bit.ly/2sDdLN6

Ministério da Educação. (2017a). Bolsistas e investimentos. Ciência sem fronteiras. Recuperado de http://www.cienciasemfronteiras.gov.br/web/csf/bolsistas-e-investimentos

Ministério da Educação. (2017b). MEC afirma que o Ciência sem Fronteiras terá 5 mil bolsistas na pósgraduação [Notícia on-line]. Recuperado de http://portal.mec.gov.br/component/content/article?id=46971

Moral, F., \& Pombo, N. (2011). Informe sociológico sobre la encuesta del valor social de las becas de la Fundación Carolina (Documento de Trabajo, num. 53). Madrid: Fundación Carolina.

Moritz, G. D. O., Moritz, M. O., \& Melo, P. A. D. (2011). A pós-graduação brasileira: evolução e principais desafios no ambiente de cenários prospectivos. In Anais do XI Colóquio Internacional sobre Gestão Universitária (pp.1-18), Instituto de Gestão e Liderança Universitária, Florianópolis. 


\section{pro.posıções}

http://dx.doi.org/10.1590/1980-6248-2017-0175

$e$-ISSN 1980-6248

Oliveira, A. L., \& Freitas, M. E. (2016). Motivações para mobilidade acadêmica internacional: a visão de alunos e professores universitários. Educação em Revista, 32(3), 217-246. doi:10.1590/0102-4698148237

Pereira, V. M. (2013). Relatos de uma politica: uma análise sobre o programa Ciência sem Fronteiras. Dissertação de Mestrado, Universidade de Brasília, Brasília, DF.

Requerimento $n^{\circ} 4$ de 2015. (2015, 19 de dezembro). Encaminha o Relatório no 21, de 2015 de Avaliação de Políticas Públicas da Comissão de Ciência, Tecnologia, Inovação, Comunicação e Informática. Diário do Senado Federal, seção 1, 10. Recuperado de http://legis.senado.leg.br/mateweb/arquivos/mate-pdf/185018.pdf

Ribeiro, D. B. (2015). Fronteiras que oprimem. Universidade e Sociedade, 24(56), 32-43.

Saldaña, P. (2016). Ciência sem Fronteiras cancela novas bolsas para alunos de graduação. Folha de São Paulo. Recuperado de http://www1.folha.uol.com.br/educacao/2016/07/1794800-ciencia-sem-fronteirasnao-vai-mais-dar-bolsa-para-aluno-de-graduacao.shtml

Schneider, S., \& Schmitt, C. J. (1998). O uso do método comparativo nas Ciências Sociais. Cadernos de Sociologia, 9, 49-87.

Souza, M. M. M. F. (2014). Avaliação das políticas linguísticas implantadas no Brasil e os programas de mobilidade acadêmica em contexto de internacionalização. Revista Ciências Humanas, 7(2), 42-59.

Stallivieri, L. (2004). Estratégias de internacionalização das universidades brasileiras. Caxias do Sul: Educs.

Submetido à avaliação em 06 de novembro de 2017; revisado em 09 de janeiro de 2019; aceito para publicação em 08 de maio de 2019. 